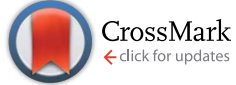

Cite this: RSC Adv., 2015, 5, 90960
Received 17th June 2015

Accepted 16th October 2015

DOI: $10.1039 / \mathrm{c} 5 \mathrm{ra11659g}$

www.rsc.org/advances

\title{
Antimicrobial and anti-adhesive activities of cell- bound biosurfactant from Lactobacillus agilis CCUG31450
}

\begin{abstract}
Eduardo J. Gudiña, ${ }^{\star}$ Elisabete C. Fernandes, José A. Teixeira and Lígia R. Rodrigues
In this work, biosurfactant production by different Lactobacillus strains was studied using the conventional MRS medium for lactic acid bacteria. Lactobacillus agilis CCUG31450 produced a cell-bound biosurfactant that reduced the surface tension of water to $42.5 \mathrm{mN} \mathrm{m}^{-1}$, and exhibited a high emulsifying activity $\left(E_{24}=\right.$ $60 \%$ ). The amount of biosurfactant produced was $84 \mathrm{mg} \mathrm{l}^{-1}$, with a $\mathrm{cmc}$ of $7.5 \mathrm{mg} \mathrm{ml}^{-1}$. A preliminary chemical characterization by Fourier transform infrared spectroscopy indicated that the biosurfactant is a glycoprotein. Using cheese whey as an alternative culture medium, biosurfactant production was increased up to $960 \mathrm{mg} \mathrm{l}^{-1}$. The biosurfactant exhibited a considerable anti-adhesive activity against Staphylococcus aureus, as well as antimicrobial activity against S. aureus, Streptococcus agalactiae and Pseudomonas aeruginosa. This study represents the first description of a biosurfactant produced by $a$. agilis strain. The results obtained open future prospects for the application of this biosurfactant to reduce or inhibit the adhesion of pathogenic microorganisms (such as S. aureus) in several biomedical applications.
\end{abstract}

\section{Introduction}

Biosurfactants are a structurally diverse group of surface-active compounds synthesized by microorganisms. They include, among others, glycolipids, lipopeptides, polysaccharideprotein complexes, phospholipids, fatty acids and neutral lipids. Due to their amphipathic nature, biosurfactants accumulate at the interface between fluid phases with different polarities, reducing the surface and interfacial tensions, and forming stable emulsions between aqueous and oil phases. ${ }^{1}$ Although the function attributable to biosurfactants in the producer organisms is not completely understood, it is generally accepted that these molecules enhance the solubility of water-insoluble compounds, facilitating their uptake into the cell, and participate in processes such as cell adhesion and aggregation, quorum sensing, biofilm formation and defense against other microorganisms. ${ }^{2}$

Many biosurfactants have been reported to possess a similar or better performance when compared with synthetic surfactants, which in addition to their lower toxicity, higher biodegradability and effectiveness at extreme temperatures, salinities and $\mathrm{pH}$ values, make them a green alternative to their chemical counterparts in different applications, including agriculture, food, cosmetics or petroleum industries, as well as in bioremediation. $^{3-5}$ Furthermore, biosurfactants can affect

CEB - Centre of Biological Engineering, University of Minho, Campus de Gualtar, 4710-057 Braga, Portugal. E-mail: egudina@deb.uminho.pt; Fax: +351 253 604429; Tel: +351253601968 microorganisms' adhesion to different surfaces, ${ }^{6,7}$ exhibit antibacterial, antifungal or antiviral activity ${ }^{8-11}$ and, in some cases, anti-tumor activity, interfering with cancer progression processes. ${ }^{\mathbf{1 , 1 2}}$ Altogether these properties contribute to the biosurfactants potential as alternatives to conventional therapeutic agents in many biomedical applications.

Lactic acid bacteria (LAB) represent a significant part of the natural microbiota in the human gastrointestinal and genitourinary tracts, playing an important role in the maintenance of homeostasis within those ecosystems and contributing to prevent pathogen colonization. These bacteria are considered probiotic agents (live microorganisms which, when administered in adequate amounts, confer a health benefit to the host) that inhibit the growth of pathogens, producing antibacterial compounds (e.g. lactic acid, hydrogen peroxide, bacteriocins, and bacteriocin-like substances) and releasing biosurfactants. ${ }^{13}$

Biosurfactants produced by LAB are less studied than other biosurfactants like lipopeptides or rhamnolipids (produced by Bacillus and Pseudomonas species, respectively) for several reasons; namely they are less effective, reducing the surface tension to values around $36-45 \mathrm{mN} \mathrm{m}^{-1}$; their critical micelle concentrations (cmc) are relatively high (from 1.0 to 20.0 $\mathrm{mg} \mathrm{ml}^{-1}$ ); they are produced in lower amounts (20-100 $\mathrm{mg} \mathrm{l}^{-1}$ ); and they are associated to the cell wall, thus an extraction process is required for their recovery. ${ }^{\mathbf{1 0 , 1 1 , 1 4}}$ However, the main advantage of these biosurfactants is that LAB are generally regarded as safe (GRAS), and most of them are already used in many food manufacturing and industrial processes. Therefore, $\mathrm{LAB}$ can be viewed as a promising source of biosurfactants. 
In this work, the biosurfactant production by different Lactobacillus strains was evaluated. The cell-bound biosurfactant produced by Lactobacillus agilis CCUG31450 was characterized. The critical micelle concentration and the effect of several environmental parameters on surface and emulsifying activities were determined. Furthermore, a preliminary chemical characterization was performed. Alternative culture media were tested for the biosurfactant production by this isolate. And the antimicrobial and anti-adhesive activities against different pathogenic microorganisms were studied.

\section{Results and discussion}

\subsection{Screening of biosurfactant-producing strains}

The production of cell-bound and excreted biosurfactants by the different Lactobacillus strains was studied using MRS medium. None of the isolates could reduce the surface tension of the culture medium, meaning that these strains are unable to produce extracellular biosurfactants. However, all the isolates were found to produce cell-bound biosurfactants, as surface tension reductions (between 15.5 and $27.9 \mathrm{mN} \mathrm{m}^{-1}$ ) after the extraction procedure at the end of the fermentation process, were observed (Table 1). Taking into account the minimum decrease in surface tension $\left(8 \mathrm{mN} \mathrm{m}^{-1}\right)$ generally accepted to consider a microorganism as a biosurfactant-producer, ${ }^{15}$ it can be concluded that all the studied lactobacilli produced biosurfactants. The highest surface tension reduction $(27.9 \mathrm{mN}$ $\mathrm{m}^{-1}$ ) was obtained with the isolate $L$. agilis CCUG31450, which also showed the highest emulsifying activity (20.0\%) and the highest biosurfactant production $\left(84.4 \mathrm{mg} \mathrm{l}^{-1}\right)$. Surface tension reductions after extraction of cell-bound biosurfactants between 12 and $33 \mathrm{mN} \mathrm{m}^{-1}$ have been reported for different Lactobacillus species, ${ }^{\mathbf{6 , 9 , 1 6 - 2 0}}$ which is in good agreement with the results obtained with the strains herein studied. Although LAB produce mainly cell-bound biosurfactants, in some cases cellbound and extracellular biosurfactants are produced simultaneously; however, in those cases, extracellular biosurfactants are usually produced in lower amounts. ${ }^{17-21}$ On the contrary, in the last years, a few Lactobacillus and Lactococcus species have been reported to exclusively produce extracellular biosurfactants. ${ }^{22-25}$

The amounts of cell-bound biosurfactants produced by other LAB vary between 20 and $100 \mathrm{mg} \mathrm{l}^{-1} \cdot{ }^{\mathbf{1 0 , 1 1 , 1 9 - 2 1 , 2 6}}$ In the case of lactobacilli producing exclusively extracellular biosurfactants, the amounts reported are usually higher $\left(1-5 \mathrm{~g} \mathrm{l}^{-1}\right) .^{\mathbf{2 2 , 2 4 , 2 5}}$ Therefore, the amounts of cell-bound biosurfactant produced by L. agilis CCUG31450 are in accordance with the previously reported data for other LAB. In view of the results obtained, $L$. agilis CCUG31450 was selected to perform the following studies, as it showed the best results regarding biosurfactant production.

\subsection{Critical micelle concentration (cmc)}

The cmc of the cell-bound biosurfactant produced by L. agilis CCUG31450 in MRS medium was determined by measuring the surface tension of the freeze-dried biosurfactant dissolved at different concentrations in PBS buffer, as described elsewhere ${ }^{\mathbf{1 0}}$ (Fig. 1). The cmc was found to be $7.5 \mathrm{mg} \mathrm{ml}^{-1}$, with a minimum surface tension value of $42.5 \mathrm{mN} \mathrm{m}^{-1}$, and a maximum emulsifying index of $60 \%$.

The cmc and the surface tension values herein obtained for the cell-bound biosurfactant produced by L. agilis CCUG31450 are in good agreement with the values reported in the literature for biosurfactants produced by other LAB, although lactobacilli

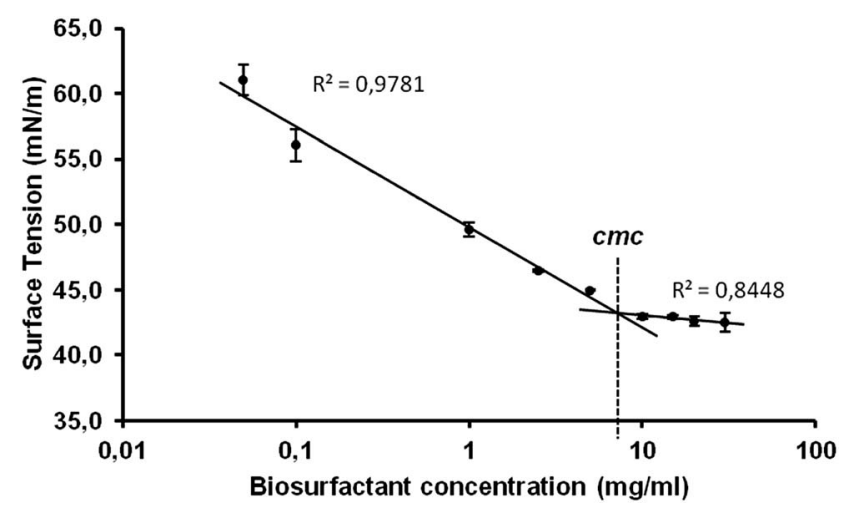

Fig. 1 Surface tension values $\left(\mathrm{mN} \mathrm{m}^{-1}\right)$ versus logarithm of biosurfactant concentration ( $\mathrm{mg} \mathrm{ml}^{-1}$ ) obtained with the cell-bound biosurfactant produced by L. agilis CCUG31450 in MRS medium. The $\mathrm{cmc}$ was determined from the intersection of the regression lines that better describe the two parts of the curve, below and above the cmc. Results represent the average of two independent experiments \pm standard deviation.

Table 1 Screening of biosurfactant production by lactobacilli. Surface tension values $\left(\mathrm{mN} \mathrm{m}^{-1}\right)$, emulsifying indexes $\left(E_{24}\right.$, \%), biomass concentration $\left(\mathrm{OD}_{600} \mathrm{~nm}\right)$ and cell-bound biosurfactant concentration $\left(\mathrm{mg} \mathrm{l}^{-1}\right)$ obtained with the different lactobacilli strains grown in MRS medium at $37{ }^{\circ} \mathrm{C}$ and $100 \mathrm{rpm}$. The surface tension values and the emulsifying indexes were measured in the PBS extracts after the recovery of the cell-bound biosurfactants. The surface tension of PBS was $71.9 \pm 0.1 \mathrm{mN} \mathrm{m}^{-1}$. Results represent the average of three independent experiments \pm standard deviation

\begin{tabular}{|c|c|c|c|c|c|}
\hline Microorganism & $t(\mathrm{~h})$ & $\mathrm{ST}\left(\mathrm{mN} \mathrm{m}^{-1}\right)$ & $\mathrm{OD}_{600 \mathrm{~nm}}$ & $E_{24}(\%)$ & [Biosurfactant $]\left(\mathrm{mg} \mathrm{l}^{-1}\right)$ \\
\hline L. agilis CCUG31450 & 96 & $44.0 \pm 0.4$ & $1.042 \pm 0.156$ & $20.0 \pm 2.0$ & $84.4 \pm 1.6$ \\
\hline L. animalis ATCC35046 & 120 & $46.6 \pm 1.4$ & $1.635 \pm 0.108$ & $16.0 \pm 1.2$ & $27.6 \pm 5.6$ \\
\hline L. buchneri ATCC4005 & 72 & $56.0 \pm 2.1$ & $1.876 \pm 0.243$ & 0.0 & $18.6 \pm 3.7$ \\
\hline L. hamsteri ATCC43851 & 96 & $52.9 \pm 1.1$ & $4.065 \pm 0.134$ & 0.0 & $24.2 \pm 1.6$ \\
\hline L. intestinalis ATCC49335 & 72 & $56.4 \pm 0.9$ & $1.289 \pm 0.201$ & 0.0 & $19.0 \pm 4.2$ \\
\hline
\end{tabular}


strains that produce exclusively extracellular biosurfactants can exhibit lower cmc values (Table 2).

The biosurfactant produced by L. agilis CCUG31450 exhibited an emulsifying index of $60 \%$ against $n$-hexadecane at concentrations equal or higher than the cmc. This emulsifying index is higher than the results reported for biosurfactants produced by other LAB. Emulsifying indexes between 40 and $49 \%$ were found for biosurfactants produced by Lactobacillus pentosus CECT4023 against gasoline, kerosene and octane; ${ }^{3,27}$ and biosurfactants produced by Lactobacillus plantarum CFR2194 exhibited emulsifying indexes against a variety of water-immiscible substrates between 13.6 and $38.2 \%{ }^{9}$

\subsection{Stability studies}

The effect of several environmental parameters on the activity of the cell-bound biosurfactant produced by L. agilis CCUG31450 was studied at a concentration of $7.5 \mathrm{mg} \mathrm{ml}^{-1}$ (the cmc for this biosurfactant).

Regarding the effect of $\mathrm{pH}$, the minimum surface tension was obtained at $\mathrm{pH} 7$. For $\mathrm{pH}$ values lower than 7 , an increase in the surface tension values was observed (from $42.8 \mathrm{mN} \mathrm{m}^{-1}$ at $\mathrm{pH} 7$ to $45.0 \mathrm{mN} \mathrm{m}^{-1}$ at $\mathrm{pH}$ 6). As the $\mathrm{pH}$ decreases, the surface tension continued increasing, up to $47.0 \mathrm{mN} \mathrm{m}^{-1}$ at $\mathrm{pH} 2$. However, the emulsifying activity was less affected by low $\mathrm{pH}$ values $(60.0 \%$ at $\mathrm{pH} 7$ and $57.0 \%$ at $\mathrm{pH} 3)$. Under alkaline conditions, from $\mathrm{pH} 7$ to 9 , only a slight increase in the surface tension was found, and the emulsifying activity remained constant. However, for $\mathrm{pH}$ values higher than 9, a rapid increase in the surface tension values was detected, as well as a reduction in the emulsifying activity, which disappeared at $\mathrm{pH}$ values higher than 11 . The most favorable conditions regarding surface and emulsifying activity were obtained between $\mathrm{pH} 7$ and 9 (Fig. 2A).

The instability of biosurfactants produced by some LAB when exposed to acidic conditions, as well as a higher stability at alkaline conditions, has been previously reported by other researchers. ${ }^{\mathbf{1 0 , 1 1 , 1 4 , 2 7}}$ The characterization of some of those

Table 2 Critical micelle concentrations $\left(\mathrm{mg} \mathrm{ml}^{-1}\right)$ and surface tension values $\left(\mathrm{mN} \mathrm{m}^{-1}\right)$ reported for biosurfactants produced by different $L A B$

\begin{tabular}{|c|c|}
\hline $\begin{array}{l}\text { Surface } \\
\text { tension }\end{array}$ & $\begin{array}{l}\mathrm{cmc} \\
\left(\mathrm{mo} \cdot \mathrm{ml}^{-1}\right)\end{array}$ \\
\hline
\end{tabular}

Cell-bound biosurfactants Lactobacillus plantarum CFR2194 Lactococcus lactis 53 Streptococcus thermophilus A Lactobacillus paracasei $\mathrm{A} 20$ Lactobacillus fermenti 126 Lactobacillus rhamnosus CCM1825 Lactobacillus acidophilus RC14 Lactobacillus agilis CCUG31450

$\begin{array}{rrl}44.3 & 6.0 & 9 \\ 36.0 & 14.0 & 10 \\ 36.0 & 20.0 & 11 \\ 41.8 & 2.5 & 14 \\ 45.1 & 9.0 & 16 \\ 43.6 & 6.0 & 16 \\ 39.0 & 1.0 & 20 \\ 42.5 & 7.5 & \text { This study }\end{array}$

Extracellular biosurfactants Lactobacillus sp. CV8LAC Lactococcus lactis

$\begin{array}{lll}45.4 & 0.1 & 22 \\ 40.5 & 3.5 & 24\end{array}$
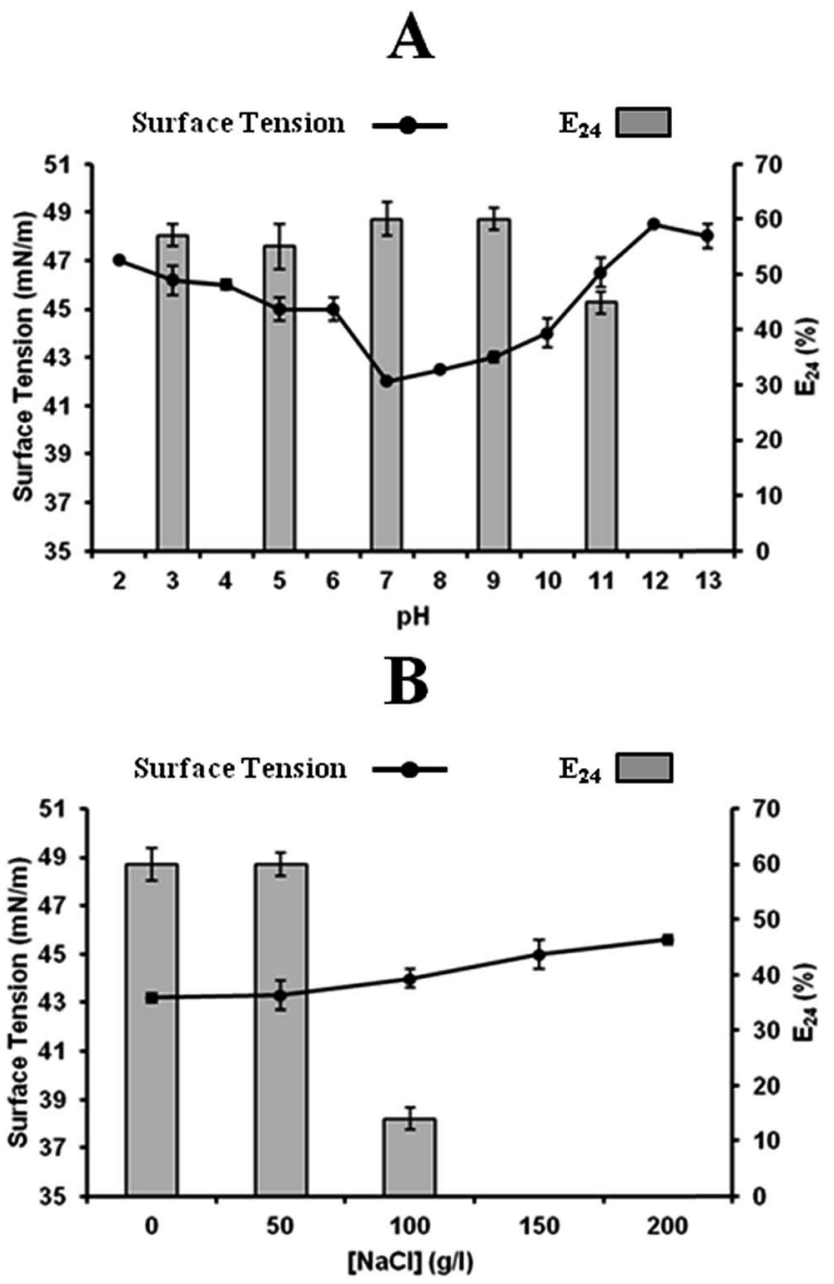

Fig. 2 Effect of $\mathrm{pH}(\mathrm{A})$ and salinity (B) on the surface tension and the emulsifying activity of the cell-bound biosurfactant produced by $L$. agilis CCUG31450 dissolved in demineralized water at a concentration of $7.5 \mathrm{mg} \mathrm{ml}^{-1}$. Results represent the average of three independent experiments \pm standard deviation.

biosurfactants revealed the presence of protein fractions probably associated to phosphate groups, which can be negatively affected by the denaturation at acidic pHs. ${ }^{10,11}$ Also, negatively charged groups at the polar ends of the molecules, which are protonated at low $\mathrm{pH}$ values, contribute to the biosurfactants instability in those conditions. ${ }^{\mathbf{1 4}}$

Regarding the effect of salinity, both surface tension and emulsifying activity remained almost constant for $\mathrm{NaCl}$ concentrations up to $50 \mathrm{mg} \mathrm{ml}^{-1}$ (Fig. 2B). In this case, the emulsifying activity was more affected at high $\mathrm{NaCl}$ concentrations than the surface tension. A surface tension value of 45.6 $\mathrm{mN} \mathrm{m}^{-1}$ was obtained with the highest $\mathrm{NaCl}$ concentration tested $\left(200 \mathrm{mg} \mathrm{ml}^{-1}\right)$, whereas $\mathrm{NaCl}$ concentrations higher than $50 \mathrm{mg} \mathrm{ml}^{-1}$ led to an abrupt loss of emulsifying activity.

Furthermore, the biosurfactant was found to be very stable when exposed to high temperatures, since the surface tension value $\left(42.8 \mathrm{mN} \mathrm{m}^{-1}\right)$ and the emulsifying index (60\%) remained constant after incubation at $121{ }^{\circ} \mathrm{C}$ for 20 minutes. On the contrary, Gudiña et al. ${ }^{\mathbf{1 4}}$ reported some loss of activity for the 
biosurfactant produced by Lactobacillus paracasei ssp. paracasei A20 when it was incubated at $60{ }^{\circ} \mathrm{C}$ for 120 hours; and PortillaRivera et $a l .{ }^{27}$ reported that biosurfactants produced by $L$. pentosus CECT4023 were only stable in the range of temperatures between 10 and $40{ }^{\circ} \mathrm{C}$.

\subsection{Fourier transform infrared spectroscopy (FTIR)}

The molecular characterization of the cell-bound biosurfactant produced by L. agilis CCUG31450 in MRS medium was performed using Fourier Transform Infrared spectroscopy (FTIR), which is a useful technique to identify different functional groups in mixtures of unknown composition. This technique has been widely used to obtain a preliminary characterization of complex biosurfactant mixtures produced by different lactobacilli. The most relevant peaks obtained (Fig. 3) are described below.

The broad peak at $3250 \mathrm{~cm}^{-1}$ indicates the presence of $\mathrm{OH}$ and $\mathrm{NH}$ groups, characteristic of proteins. The big and well defined peaks at $1643 \mathrm{~cm}^{-1}$ and $1535 \mathrm{~cm}^{-1}$ correspond to $\mathrm{C}=\mathrm{O}$ stretching (AMI protein band) and $\mathrm{N}-\mathrm{H}$ bending (AMII protein band), respectively. These groups suggest the presence of proteins in the sample. The small peak at $2925 \mathrm{~cm}^{-1}$, corresponding to $\mathrm{C}-\mathrm{H}$ stretching and the very small peak at 1460 $\mathrm{cm}^{-1}$, corresponding to $\mathrm{CH}$ (scissor), indicate the presence of bonds occurring in aliphatic chains. At $1060 \mathrm{~cm}^{-1}$, a large, broad and well defined peak corresponding to the PII polysaccharide band typical of bond vibrations in the $\mathrm{C}-\mathrm{O}-\mathrm{C}$ group was observed. Moreover, a small but well defined peak was observed at $1394 \mathrm{~cm}^{-1}\left(1000-1300 \mathrm{~cm}^{-1}\right)$, corresponding to $\mathrm{C}-\mathrm{O}$ stretching in sugars.

The spectrum obtained for the cell-bound biosurfactant produced by $L$. agilis CCUG31450 suggests that it must be a glycoprotein, and it is closely related to those obtained by other authors for biosurfactants produced by L. pentosus CECT4023, Lactococcus lactis 53, L. paracasei ssp. paracasei A20, L. plantarum CFR2194 or Lactobacillus fermentum ATCC9338..$^{3,9,10,28}$
The existing information on the chemical structure of biosurfactants produced by lactobacilli is very limited, mainly due to their complexity. Some of them (i.e. Lactobacillus fermenti 126, Lactobacillus rhamnosus CCM1825, Lactobacillus acidophilus DSM20079, L. lactis 53, Streptococcus thermophilus A) have been partially characterized as multi-component mixtures, consisting of protein and polysaccharides associated to phosphate groups. ${ }^{10,11,16,17,20,21,29}$ In other cases, they have been found to be glycolipids (Streptococcus mitis BA and $S$. mitis BMS $)^{30}$ or a mixture of polysaccharides and glycolipids (S. thermophilus B). ${ }^{26}$

\subsection{Alternative culture media}

In order to reduce the production costs, cheese whey was evaluated as an alternative substrate for biosurfactant production by $L$. agilis CCUG31450. The best results regarding biosurfactant production were obtained with a medium containing cheese whey at a concentration of $100 \mathrm{~g} \mathrm{l}^{-1}$. This medium contained, per liter, $34.9 \pm 0.8 \mathrm{~g}$ of carbohydrates and $8.0 \pm 0.9 \mathrm{~g}$ of protein. The cultures were performed at $37{ }^{\circ} \mathrm{C}$ and $100 \mathrm{rpm}$ for 120 hours. Similarly to the results obtained with MRS medium, the surface tension of the culture medium supernatants remained constant along the fermentation, thus no extracellular biosurfactants were produced. However, the production of cellbound biosurfactants was confirmed since the surface tension of the PBS after the extraction of cell-bound biosurfactants at the end of the fermentation was reduced up to $49.3 \mathrm{mN} \mathrm{m}^{-1}$. The amount of crude biosurfactant recovered was $959 \pm 9.9 \mathrm{mg}$ $1^{-1}$, which is about 11 times the amount of biosurfactant produced in MRS medium. However, this biosurfactant exhibited a higher cmc value $\left(13 \mathrm{mg} \mathrm{ml}^{-1}\right)$ when compared with the one produced in MRS medium.

Cheese whey, containing high levels of lactose, protein, organic acids and vitamins, has been described as a good substrate for biosurfactant production by LAB. Rodrigues et al. ${ }^{\mathbf{1 1}}$ reported the production of $1400 \mathrm{mg}$ of biosurfactant per liter by L. pentosus CECT4023 using cheese whey as culture medium. Moreover, L. lactis 53 and S. thermophilus A produced higher

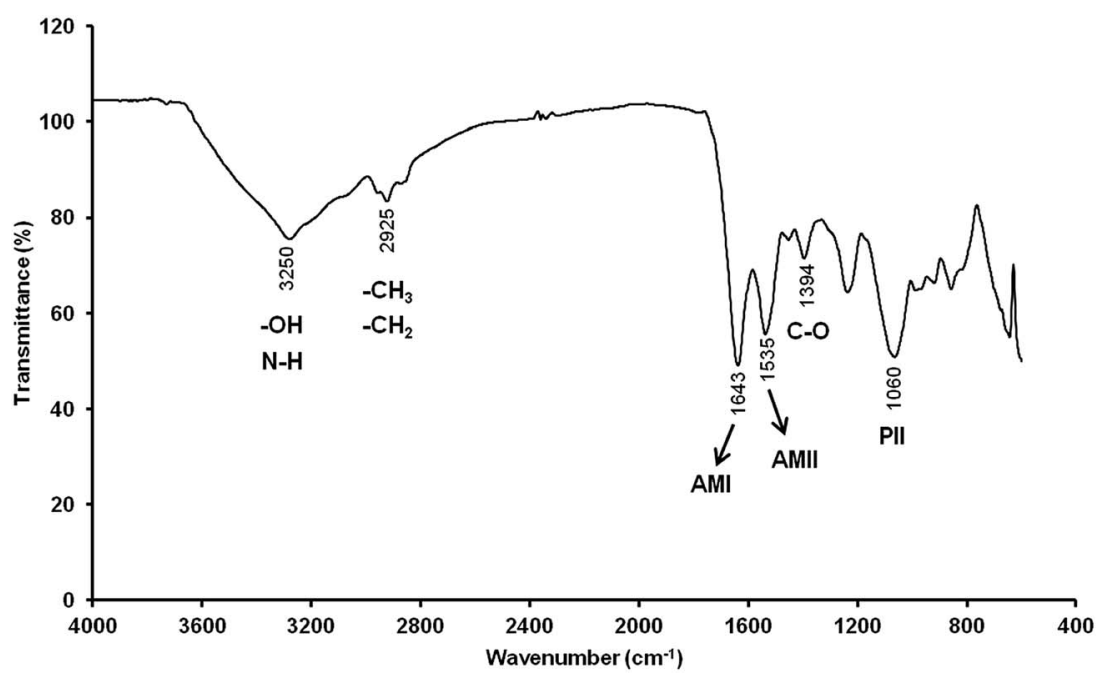

Fig. 3 FTIR spectrum obtained with the cell-bound biosurfactant produced by L. agilis CCUG31450 in MRS medium. 
amounts of biosurfactant using cheese whey supplemented with peptone or yeast extract when compared with the corresponding synthetic media. ${ }^{31}$ The results herein obtained confirm that cheese whey can be used as an alternative culture medium for biosurfactant production by L. agilis CCUG31450. The amount of biosurfactant produced with this medium is considerably higher when compared with the conventional MRS medium, thus it can contribute to reduce the production costs of this biosurfactant and increase its competitiveness in the market.

\subsection{Anti-adhesive activity}

The anti-adhesive activity of the cell-bound biosurfactant produced by L. agilis CCUG31450 was evaluated. The biosurfactant exhibited a considerable anti-adhesive activity against $S$. aureus, even at the lowest concentration tested $(1 \mathrm{mg}$ $\mathrm{ml}^{-1}$ ), which was higher than the reported for biosurfactants produced by other LAB at the same concentrations (Table 3). However, no anti-adhesive activity could be observed against the other microorganisms studied.

Studies performed with biosurfactants produced by different LAB demonstrated their ability to reduce or inhibit the adhesion of pathogenic microorganisms (including Gram-positive and Gram-negative bacteria, yeasts and filamentous fungi) to glass, polystyrene, silicone rubber, surgical implants, voice prostheses, metallic surfaces and epithelial cell surfaces. ${ }^{6,7,9,16,17,20,22,26,28-30,32-36}$ Consequently, biosurfactant treatments can provide an optional way for controlling biofilm development and inhibit the adhesion of pathogens, reducing the use of synthetic drugs and chemicals.

The anti-adhesive activity exhibited by the cell-bound biosurfactant produced by $L$. agilis CCUG31450 against $S$. aureus (a common cause of community and hospital acquired infections) opens future prospects regarding its possible application to

Table 3 Anti-adhesive activity of cell-bound biosurfactants produced by Lactobacillus agilis CCUG31450 against Staphylococcus aureus (results represent the average of triplicate experiments \pm standard deviation) compared with the results obtained with biosurfactants produced by different $L A B$

\begin{tabular}{lrll}
\hline & $\begin{array}{c}\text { Biosurfactant } \\
\text { concentration } \\
\left(\mathrm{mg} \mathrm{ml}^{-1}\right)\end{array}$ & $\begin{array}{l}\text { Anti- } \\
\text { adhesive } \\
\text { activity (\%) }\end{array}$ & Reference \\
\hline L. agilis CCUG31450 & 10.0 & $64.6 \pm 0.7$ & This study \\
& 5.0 & $62.7 \pm 1.2$ & \\
& 2.5 & $56.3 \pm 0.6$ & \\
L. paracasei ssp. & 1.0 & $50.3 \pm 3.2$ & \\
paracasei A20 & 12.5 & $62.0 \pm 1.1$ & 8 \\
& 6.2 & $51.1 \pm 1.4$ & \\
L. plantarum CFR 2194 & 3.1 & $10.3 \pm 1.2$ & \\
L. lactis 53 & 4.0 & $25.9 \pm 0.1$ & 9 \\
& 10.0 & 37 & 10 \\
S. thermophilus A & 5.0 & 34 & \\
& 2.5 & 13 & \\
& 10.0 & $42 \pm 0$ & 11 \\
& 5.0 & $22 \pm 1$ & \\
& 2.5 & $11 \pm 1$ &
\end{tabular}

reduce the adhesion of $S$. aureus on different surfaces and prevent biofilm formation and microbial colonization on different materials, such as medical insertional devices.

Usually the effect of biosurfactants on the adhesion of undesirable microorganisms is attributed to modifications in bacterial-surface interactions, like changes in the surface tension and bacterial cell-wall charge, or changes in the surface properties, which affect the adhesion and detachment of microorganisms. However, in most cases the precise mechanisms of such activity have not been fully explained, and more complex mechanisms can be involved.

Heinemann and co-workers ${ }^{33}$ isolated a collagen-binding protein from the crude biosurfactant produced by L. fermentum RC-14 which is involved in the adhesion of lactobacilli to the epithelium. At the same time, that protein inhibited the adhesion of uropathogenic bacteria probably by competition with the pathogens for binding to host sites. Likewise, that protein was proposed as the responsible for inhibiting the adhesion of $S$. aureus to biosurfactant-treated surgical implants in vivo probably due to the competition with extracellular matrix-binding proteins of $S$. aureus for binding to host sites. ${ }^{32}$ Similar collagen-binding proteins were identified in biosurfactants produced by L. rhamnosus and Lactobacillus casei strains ${ }^{37}$ and it is supposed that these proteins are involved in the biosurfactants anti-adhesive activity.

Biosurfactants released by $L$. fermentum ATCC9338 and $L$. acidophilus DSM20079 reduced the adhesion and biofilm formation of Streptococcus mutans, one of the main organisms responsible for dental caries, due to a complex process that alters the expression of genes in the target microorganism. ${ }^{28,29}$ Therefore, the exact mechanisms involved in the protective effect of biosurfactants still remain to be clarified and a better knowledge of their composition is required to completely understand their activities.

\subsection{Antimicrobial activity}

The cell-bound biosurfactant produced by L. agilis CCUG31450 exhibited antimicrobial activity at the highest concentration tested $\left(5 \mathrm{mg} \mathrm{ml}^{-1}\right)$ against $S$. aureus $(20.0 \pm 8.1 \%)$, P. aeruginosa $(13.5 \pm 0.7 \%)$ and $S$. agalactiae $(10.7 \pm 2.7 \%)$. However, no antimicrobial activity was observed against $E$. coli and $C$. albicans.

Usually, the beneficial effect of biosurfactants produced by $\mathrm{LAB}$ is due to their anti-adhesive activity. However, some few studies on their antimicrobial activity have been reported. Purified fractions of cell-bound biosurfactants produced by $S$. thermophilus A and L. lactis 53 exhibited significant antimicrobial activity against Staphylococcus epidermidis, Streptococcus salivarius, S. aureus, Candida tropicalis and C. albicans at

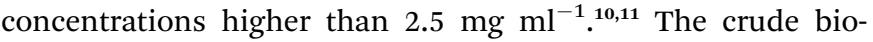
surfactant produced by L. paracasei ssp. paracasei A20 exhibited growth inhibition percentages (at a concentration of $3 \mathrm{mg} \mathrm{ml}^{-1}$ ) against $S$. aureus, $P$. aeruginosa and $S$. agalactiae of $63.1 \pm 0.4$, $50.9 \pm 0.8$ and $51.5 \pm 0.8 \%$, respectively. ${ }^{8}$ Also, the crude biosurfactant produced by $L$. plantarum CFR2194 completely inhibited the growth of $E$. coli, $S$. aureus and Yersinia 
enterocolitica at a concentration of $25 \mathrm{mg} \mathrm{ml}^{-1} .^{9}$ The extracellular biosurfactant produced by a $L$. lactis strain partially inhibited the growth of $E$. coli and $S$. aureus strains as determined by agar well diffusion assays, although the biosurfactant concentration used in these assays was not provided. ${ }^{24}$

\section{Experimental}

\subsection{Strains and standard culture conditions}

The following strains were screened for biosurfactant production: Lactobacillus animalis ATCC35046, Lactobacillus buchneri ATCC4005, Lactobacillus hamsteri ATCC43851 and Lactobacillus intestinalis ATCC49335, obtained from the American Type Culture Collection (USA); Lactobacillus agilis CCUG31450, obtained from the Culture Collection of University of Gothenburg (Sweden). All strains were grown in DeMan, Rogosa and Sharpe (MRS) medium (OXOID, England) at $37^{\circ} \mathrm{C}$ and aerobic conditions for different time intervals.

For the antimicrobial and anti-adhesive assays, the following strains, kindly provided by the Faculty of Pharmacy, University of Porto (Portugal), were used: Escherichia coli, Pseudomonas aeruginosa, Staphylococcus aureus, Streptococcus agalactiae and Candida albicans. These strains were grown overnight in LuriaBertani (LB) medium at $37{ }^{\circ} \mathrm{C}$ and aerobic conditions. The composition of LB medium was $\left(\mathrm{g} \mathrm{l}^{-1}\right)$ : $\mathrm{NaCl} 10$; tryptone 10; yeast extract 5 ; pH 7.0.

All strains were stored at $-80{ }^{\circ} \mathrm{C}$ in the appropriate medium supplemented with glycerol $(20 \%(\mathrm{v} / \mathrm{v}))$ until use. Whenever required, frozen stocks were streaked on agar plates and incubated overnight at $37{ }^{\circ} \mathrm{C}$ for further culturing.

\subsection{Screening of biosurfactant-producing strains}

Biosurfactant production by the lactobacilli strains was conducted in $500 \mathrm{ml}$ flasks containing $200 \mathrm{ml}$ of MRS medium. Each flask was inoculated with $2 \mathrm{ml}$ of a pre-culture grown overnight at $37^{\circ} \mathrm{C}$ and $100 \mathrm{rpm}$. Pre-cultures were prepared by transferring a single colony from an agar plate into $10 \mathrm{ml}$ of MRS medium. The cultures were incubated at the same conditions as the corresponding pre-cultures.

In order to evaluate bacterial growth and excreted biosurfactant production, samples $(4 \mathrm{ml})$ were taken at different time points during the fermentation. Biomass concentration was determined by measuring the optical density at $600 \mathrm{~nm}$. After measuring the cell growth, the samples were centrifuged (9000 rpm, $20 \mathrm{~min}$ ) and the cell-free supernatants were used to measure the surface tension as described below.

Biosurfactants can be excreted to the culture medium (extracellular biosurfactants) or remain attached to the cell wall (cell-bound biosurfactants). LAB have been reported to mainly produce cell-bound biosurfactants. The surface tension measured in the cell-free supernatants gives an indication of the extracellular biosurfactants produced; while the production of cell-bound biosurfactants is determined at the end of the fermentation after their recovery (as described below) and further measurement of the surface tension values. All the cultures were maintained until the maximum biosurfactant production was achieved (i.e. until the surface tension values remained constant).

\subsection{Cell-bound biosurfactants recovery}

At the end of the fermentation, the cells were harvested by centrifugation (9000 rpm, $20 \mathrm{~min}$ ), washed twice with the same volume of demineralized water, and resuspended in phosphate-

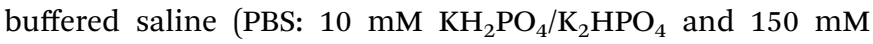
$\mathrm{NaCl}$, with $\mathrm{pH}$ adjusted to 7.0), as described by Gudiña $e$ e $a l .{ }^{14} \mathrm{~A}$ volume of $15 \mathrm{ml}$ of PBS buffer was used per $100 \mathrm{ml}$ of culture. The cell-suspension was left at room temperature $\left(20^{\circ} \mathrm{C}\right)$ for $2 \mathrm{~h}$ with gentle stirring for cell-bound biosurfactants release. Subsequently, the cells were removed by centrifugation (9000 $\mathrm{rpm}, 20 \mathrm{~min}$ ) and the remaining supernatant liquid was filtered through a $0.2 \mu \mathrm{m}$ pore-size filter (Whatman, GE Healthcare, UK). The solution containing the cell-bound biosurfactants was dialyzed against demineralized water at $4{ }^{\circ} \mathrm{C}$ in a Cellu-Sep $\odot$ membrane (molecular weight cut-off 6000-8000 Dalton; Membrane Filtration Products, Inc., USA) for $48 \mathrm{~h}$ and further freeze-dried. The biosurfactants were weighed and stored at $-20{ }^{\circ} \mathrm{C}$ for subsequent studies. To confirm the biosurfactant production, the surface tension was routinely measured (as described below) during the extraction process.

\subsection{Surface-activity determination}

The surface tension of the culture broth supernatants, biosurfactant solutions and the PBS extracts was measured using the Ring method as described elsewhere. ${ }^{\mathbf{1 4}}$ A KRÜSS K6 Tensiometer (KRÜSS GmbH, Germany) equipped with a $1.9 \mathrm{~cm}$ De Noüy platinum ring was used. In order to increase the accuracy of the surface tension measurements, an average of triplicates was determined. All the measurements were performed at room temperature $\left(20^{\circ} \mathrm{C}\right)$.

\subsection{Emulsifying activity determination}

Emulsifying activity was determined by the addition of $2 \mathrm{ml}$ of $n$ hexadecane to the same volume of biosurfactant solutions or PBS extracts in glass test tubes, as described elsewhere. ${ }^{\mathbf{4} 5}$ The tubes were mixed with vortex at high speed for $2 \mathrm{~min}$ and subsequently incubated at $25{ }^{\circ} \mathrm{C}$ for $24 \mathrm{~h}$. The emulsification indexes $\left(E_{24}, \%\right)$ were calculated as the percentage of the height of the emulsified layer $(\mathrm{mm})$ divided by the total height of the liquid column (mm). All the emulsification indexes were performed in triplicate.

\subsection{Critical micelle concentration (cmc)}

Critical micelle concentration (cmc) is defined as the concentration of an amphiphilic compound in solution at which the formation of micelles is initiated. Cell-bound biosurfactants produced by L. agilis CCUG31450 were dissolved in PBS buffer at different concentrations (from 0.05 to $50 \mathrm{mg} \mathrm{ml}^{-1}$ ), and the surface tension of each sample was measured as described above. The cmc was determined by plotting the surface tension as a function of the logarithm of biosurfactant concentration, and it was found at the point of intersection between the two 
lines that best fit through the pre- and post-cmc data, as described elsewhere. ${ }^{\mathbf{1 4}}$ All the measurements were done in triplicate.

\subsection{Stability studies}

The applicability of biosurfactants can be conditioned by their stability to different environmental parameters. Therefore, the effect of $\mathrm{pH}$, temperature and salinity on the activity of the biosurfactant produced by L. agilis CCUG31450 in MRS medium was determined. Stability studies were performed using the cellbound freeze-dried biosurfactant dissolved in demineralized water at a concentration equivalent to the cmc. In order to assess the effect of salinity on biosurfactant activity, the biosurfactant solutions were supplemented with different $\mathrm{NaCl}$ concentrations (from 10 to $200 \mathrm{~g} \mathrm{l}^{-1}$ ). The surface tension and the emulsifying activity were measured as described above and compared with the corresponding values without addition of $\mathrm{NaCl}$. The stability of the biosurfactant to high temperatures was also determined. For that purpose, the biosurfactant solutions were incubated at $121{ }^{\circ} \mathrm{C}$ for $20 \mathrm{~min}$ and allowed to cool to room temperature. Surface tension and emulsification indexes were measured and compared to the corresponding values before the heat treatment. The $\mathrm{pH}$ stability was studied by adjusting the biosurfactant solutions to different $\mathrm{pH}$ values (213) using $\mathrm{HCl}$ or $\mathrm{NaOH}$ solutions, and measuring the surface tension and the emulsification indexes as described above. All the experiments were carried out in triplicate.

\subsection{Fourier transform infrared spectroscopy (FTIR)}

Fourier transform infrared spectroscopy in the attenuated total reflection mode (FTIR-ATR) was used to study the molecular composition of the cell-bound biosurfactant produced by L. agilis CCUG31450 in MRS medium. The spectra were recorded on a JASCO FTIR-4100 Spectrometer and were obtained from 64 scans with a resolution of $8 \mathrm{~cm}^{-1}$ in the range of $600-4000 \mathrm{~cm}^{-1}$.

\subsection{Alternative culture media}

Biosurfactant production by L. agilis CCUG31450 was studied using cheese whey powder (supplied by a local dairy industry, Quinta dos Ingleses, S.A.) as an alternative substrate to replace the synthetic medium MRS. Cheese whey media (CWM) were prepared by dissolving cheese whey in demineralized water at different concentrations (between 50 and $150 \mathrm{~g} \mathrm{l}^{-1}$ ). The solutions were sterilized $\left(121^{\circ} \mathrm{C}\right.$ for 15 minutes $)$ and the precipitates (i.e. proteinaceous material) were removed by centrifugation (9000 rpm, $40 \mathrm{~min}$ ) and discharged. The supernatants obtained were adjusted to $\mathrm{pH} 6.2$ and used as culture media. The CWM were analyzed for total carbohydrates and protein contents using the phenol-sulfuric and Lowry methods, respectively. ${ }^{38,39}$

\subsection{Anti-adhesive assays}

The anti-adhesive activity of the cell-bound biosurfactant produced by $L$. agilis CCUG31450 against $E$. coli, $P$. aeruginosa, $S$. aureus, $S$. agalactiae and $C$. albicans was determined as described by Gudiña et al. ${ }^{8}$ Briefly, the wells of a sterile 96-well flat-bottomed plastic tissue culture plate (Orange Scientific, Belgium) were filled with $200 \mu \mathrm{l}$ of biosurfactant solutions prepared in demineralized water at different concentrations (between 1 and $10 \mathrm{mg} \mathrm{ml}^{-1}$ ). The plates were incubated for $18 \mathrm{~h}$ at $4{ }^{\circ} \mathrm{C}$ and subsequently washed twice with PBS buffer. An aliquot of $200 \mu \mathrm{l}$ of a washed bacterial suspension in PBS adjusted to an optical density $(600 \mathrm{~nm})$ of 0.6 was added to each well and incubated for $24 \mathrm{~h}$ at $4{ }^{\circ} \mathrm{C}$. Unattached microorganisms were removed by washing the wells twice with PBS. The adherent microorganisms were fixed with $200 \mu \mathrm{l}$ of $99 \%$ methanol per well, and after 15 min the plates were emptied and left to dry. After that, the plates were stained for $5 \mathrm{~min}$ with $200 \mu \mathrm{l}$ of $33 \%$ crystal violet (used for Gram staining) per well. Excess stain was rinsed out by washing the wells three times with PBS. Subsequently, the plates were air dried, the dye bound to the adherent microorganisms was re-solubilized with $200 \mu \mathrm{l}$ of $33 \%$ $(\mathrm{v} / \mathrm{v})$ glacial acetic acid per well, and the optical density of each well was measured at $595 \mathrm{~nm}$. The microbial inhibition percentages at different biosurfactant concentrations for each microorganism were calculated as:

$$
\% \text { microbial inhibition }_{c}=\left[1-\left(\mathrm{OD}_{c} / \mathrm{OD}_{0}\right)\right] \times 100,
$$

where $\mathrm{OD}_{c}$ represents the optical density of the well with a biosurfactant concentration $c$, and $\mathrm{OD}_{0}$ is the optical density of the control well (without biosurfactant). Triplicate assays were performed for each microorganism and biosurfactant concentration.

\subsection{Antimicrobial assays}

The antimicrobial activity of the cell-bound biosurfactant produced by L. agilis CCUG31450 against the same microorganisms used in the anti-adhesive assays was determined in 96well plastic tissue culture plates (Orange Scientific, Belgium) at different concentrations, as described by Gudiña et al. ${ }^{8}$ Briefly, the freeze-dried biosurfactant was dissolved in LB medium at a concentration of $5 \mathrm{mg} \mathrm{ml} \mathrm{m}^{-1}$, and sterilized by filtration through a $0.2 \mu \mathrm{m}$ pore-size filter (Whatman, GE Healthcare, UK). Subsequently, $250 \mu \mathrm{l}$ of LB medium containing the biosurfactant were placed into the first column of the 96-well microplate, and $125 \mu \mathrm{l}$ of LB medium in the remaining wells. After that, $125 \mu \mathrm{l}$ from the first column were transferred to the second column and mixed. Serially, $125 \mu \mathrm{l}$ were transferred to the subsequent wells, discarding $125 \mu$ l of the mixture in the tenth column. This process results in two-fold serial dilutions of the biosurfactant in the first 10 columns. Columns 11 and 12 did not contain biosurfactant and served as growth and negative controls, respectively. All the wells (except for the $12^{\text {th }}$ column) were inoculated with $5 \mu \mathrm{l}$ of a pre-culture of the corresponding microorganism grown overnight in LB medium at $37{ }^{\circ} \mathrm{C}$ and diluted to an optical density $(600 \mathrm{~nm})$ of 0.3 . The microplates were covered and incubated for $24 \mathrm{~h}$ at $37^{\circ} \mathrm{C}$. After $24 \mathrm{~h}$ of incubation, the optical density of each well (at $600 \mathrm{~nm}$ ) was measured. The growth inhibition percentages at different biosurfactant concentrations for each microorganism were calculated as: 


$$
\% \text { growth inhibition }{ }_{c}=\left[1-\left(\mathrm{OD}_{c} / \mathrm{OD}_{0}\right)\right] \times 100,
$$

where $\mathrm{OD}_{c}$ represents the optical density of the well with a biosurfactant concentration $c$, and $\mathrm{OD}_{0}$ is the optical density of the control well (without biosurfactant). Triplicate assays were performed for each microorganism and biosurfactant concentration.

\section{Conclusion}

In this work, the biosurfactant production by $L$. agilis CCUG31450 was reported for the first time. A preliminary chemical characterization by FTIR indicated that this biosurfactant is a glycoprotein. The biosurfactant exhibited higher anti-adhesive activity against $S$. aureus when compared with biosurfactants produced by other lactobacilli. It also showed antimicrobial activity against $S$. aureus, $S$. agalactiae and $P$. aeruginosa, which is an unusual property among biosurfactants produced by LAB. Furthermore, the use of cheese whey as an alternative culture medium increased the biosurfactant production about 11 times as compared with the conventional MRS medium, which can contribute to the economic sustainability of the production process. The antimicrobial and anti-adhesive activities unveiled by this biosurfactant against $S$. aureus suggest its possible use in several biomedical applications.

\section{Acknowledgements}

The authors acknowledge the financial support from the Portuguese Foundation for Science and Technology (FCT) and the European Community fund FEDER, through Program COMPETE, under the scope of the Projects FCOMP-01-0124FEDER-007025 (PTDC/AMB/68393/2006), PEst-OE/EQB/LA0023/ 2013, PEST-C/FIS/UI607/2013, RECI/BBB-EBI/0179/2012 (FCOMP-01-0124-FEDER-027462), the strategic funding of UID/ BIO/04469/2013 unit, and the Projects "BioEnv - Biotechnology and Bioengineering for a sustainable world" and "Matepro Optimizing Materials and Processes". NORTE-07-0124-FEDER000048, co-funded by the Programa Operacional Regional do Norte (ON.2 - O Novo Norte), QREN, FEDER; and from AdI (Agência de Inovação, S.A.), through the project BIOCLEAN "Development of biosurfactant-based products for surfaces cleaning and disinfection in the food industry" (QREN Ref. 30215).

\section{References}

1 E. J. Gudiña, V. Rangarajan, R. Sen and L. R. Rodrigues, Trends Pharmacol. Sci., 2013, 34, 667-675.

2 A. M. Abdel-Mawgoud, F. Lépine and E. Déziel, Appl. Microbiol. Biotechnol., 2010, 86, 1323-1336.

3 A. B. Moldes, R. Paradelo, X. Vecino, J. M. Cruz, E. J. Gudiña, L. R. Rodrigues, J. A. Teixeira, J. M. Domínguez and M. T. Barral, BioMed Res. Int., 2013, 2013, 961842, DOI: $10.1155 / 2013 / 961842$.
4 J. F. B. Pereira, E. J. Gudiña, R. Costa, R. Vitorino, J. A. Teixeira, J. A. P. Coutinho and L. R. Rodrigues, Fuel, 2013, 111, 259-268.

5 D. A. Vaz, E. J. Gudiña, E. J. Alameda, J. A. Teixeira and L. R. Rodrigues, Colloids Surf., B, 2012, 89, 167-174.

6 T. Meylheuc, C. Methivier, M. Renault, J. M. Herry, C. M. Pradier and M. N. Bellon-Fontaine, Colloids Surf., B, 2006, 52, 128-137.

7 L. R. Rodrigues, H. C. van der Mei, J. A. Teixeira and R. Oliveira, Appl. Environ. Microbiol., 2004, 70, 4408-4410.

8 E. J. Gudiña, V. Rocha, J. A. Teixeira and L. R. Rodrigues, Lett. Appl. Microbiol., 2010, 50, 419-424.

9 A. N. Madhu and S. G. Prapulla, Appl. Biochem. Biotechnol., 2014, 172, 1777-1789.

10 L. R. Rodrigues, J. A. Teixeira, H. C. van der Mei and R. Oliveira, Colloids Surf., B, 2006, 49, 78-85.

11 L. R. Rodrigues, J. A. Teixeira, H. C. van der Mei and R. Oliveira, Colloids Surf., B, 2006, 53, 105-112.

12 C. Duarte, E. J. Gudiña, C. F. Lima and L. R. Rodrigues, $A M B$ Express, 2014, 4, 40, DOI: 10.1186/s13568-014-0040-0.

13 G. Reid, J. A. Younes, H. C. Van der Mei, G. B. Gloor, R. Knight and H. J. Busscher, Nat. Rev. Microbiol., 2011, 9, 27-38.

14 E. J. Gudiña, J. A. Teixeira and L. R. Rodrigues, Colloids Surf., $B, 2010,76,298-304$.

15 H. J. Busscher, T. R. Neu and H. C. van der Mei, Appl. Microbiol. Biotechnol., 1994, 41, 4-7.

16 B. Brzozowski, W. Bednarski and P. Golek, Food Technol. Biotechnol., 2011, 49, 177-186.

17 P. Golek, W. Bednarski, B. Brzozowski and B. Dziuba, Ann. Microbiol., 2009, 59, 119-126.

18 E. J. Gudiña, J. A. Teixeira and L. R. Rodrigues, Appl. Environ. Soil Sci., 2011, 2011, 201254, DOI: 10.1155/2011/201254.

19 L. R. Rodrigues, A. Moldes, J. A. Teixeira and R. Oliveira, Biochem. Eng. J., 2006, 28, 109-116.

20 M. M. C. Velraeds, H. C. van der Mei, G. Reid and H. J. Busscher, Colloids Surf., B, 1996, 8, 51-61.

21 M. M. C. Velraeds, H. C. van der Mei, G. Reid and H. J. Busscher, Appl. Environ. Microbiol., 1996, 62, 19581963.

22 L. Fracchia, M. Cavallo, G. Allegrone and M. G. Martinotti, in Current Research, Technology and Education Topics in Applied Microbiology and Microbial Biotechnology, ed. A. MéndezVilas, Formatex, Spain, 2010, p. 827.

23 A. Mbawala and T. H. Mouafo, Int. J. Eng. Res. Ind. Appl., 2012, 2, 974-985.

24 P. Saravanakumari and K. Mani, Bioresour. Technol., 2010, 101, 8851-8854.

25 K. Thavasi, S. Jayalakshmi and I. M. Banat, Bioresour. Technol., 2011, 102, 3366-3372.

26 H. J. Busscher, C. G. van Hoogmoed, G. I. GeertsemaDoornbusch, M. van der Kuijl-Booij and H. C. van der Mei, Appl. Environ. Microbiol., 1997, 63, 3810-3817.

27 O. Portilla-Rivera, A. Torrado, J. M. Domínguez and A. B. Moldes, J. Agric. Food Chem., 2008, 56, 8074-8080.

28 A. Tahmourespour, R. Salehi, R. K. Kermanshahi and G. Eslami, Biofouling, 2011, 27, 385-392. 
29 A. Tahmourespour, R. Salehi and R. K. Kermanshahi, Braz. J. Microbiol., 2011, 42, 330-339.

30 C. G. van Hoogmoed, M. van der Kuijl-Booij, H. C. van der Mei and H. J. Busscher, Appl. Environ. Microbiol., 2000, 66, 659-663.

31 L. R. Rodrigues, J. A. Teixeira and R. Oliveira, Biochem. Eng. J., 2006, 32, 135-142.

32 B. S. Gan, J. Kim, G. Reid, P. Cadieux and J. C. Howard, J. Infect. Dis., 2002, 185, 1369-1372.

33 C. Heinemann, J. E. T. van Hylckama, D. B. Janssen, H. J. Busscher, H. C. van der Mei and G. Reid, FEMS Microbiol. Lett., 2000, 190, 177-180.
34 L. R. Rodrigues, H. C. van der Mei, I. M. Banat, J. A. Teixeira and R. Oliveira, FEMS Immunol. Med. Microbiol., 2006, 46, 107-112.

35 R. R. Spurbeck and C. G. Arvidson, Infect. Immun., 2010, 78, 3103-3111.

36 C. G. van Hoogmoed, H. C. van der Mei and H. J. Busscher, Biofouling, 2004, 20, 261-267.

37 J. C. Howard, C. Heinemann, B. J. Thatcher, B. Martin, B. S. Gan and G. Reid, Appl. Environ. Microbiol., 2000, 66, 4396-4400.

38 M. Dubois, K. A. Gille, J. K. Hamilton, P. A. Rebers and F. Smith, Anal. Chem., 1956, 28, 350-356.

39 O. H. Lowry, N. J. Rosebrough, A. L. Farr and R. J. Randall, J. Biol. Chem., 1951, 193, 265-275. 